\title{
Editorial
}

\section{Welcome to Processes-A New Open Access Journal on Chemical and Biological Process Technology}

\author{
Michael A. Henson \\ Founding Editor-in-Chief of Processes, Department of Chemical Engineering, \\ University of Massachusetts, Amherst, MA 01003-3110, USA; E-Mail: henson@ecs.umass.edu; \\ Tel.: +1-413-545-3481; Fax: +1-413-545-1647
}

Received: 10 November 2012 / Accepted: 10 November 2012 / Published: 21 November 2012

As the result of remarkable technological progress, this past decade has witnessed considerable advances in our ability to manipulate natural and engineered systems, particularly at the molecular level. These advancements offer the potential to revolutionize our world through the development of novel soft and hard materials and the construction of new cellular platforms for chemical and pharmaceutical synthesis. For these technologies to truly impact society, the development of process technology that will enable effective large-scale production is essential. Improved processes are also needed for more established technologies in chemical and biochemical manufacturing, as these industries face ever increasing competitive pressure that mandates continuous improvement.

Processes is a new open access journal that is focused on novel process technology for the chemical, materials, biochemical pharmaceutical and biomedical industries. The journal emphasizes engineered processes that have the potential to be used for manufacturing rather than simplified laboratory systems often used in purely scientific research studies. The scope includes, but is not limited to, the following topics: experimental, theoretical and computational research on process development and engineering; chemical and biochemical reaction processes; mass transfer, separation and purification processes; mixing, fluid processing and heat transfer systems; integrated process design and scale-up; process modeling, simulation, optimization and control. We are particularly interested in receiving manuscripts that integrate experimental and theoretical/computational studies as well as contributions from industry.

I am honored to have been selected as the Founding Editor-in-Chief of Processes. In my opinion, the journal offers a much needed outlet for cutting edge process related research that emphasizes practical engineering solutions. We have assembled a distinguished set of researchers to serve on the Editorial Board and to assist with journal development, manuscript review and the editing of special issues on focused topics. Together we will work with an experienced editorial office to ensure a stringent yet rapid peer review process and professional, timely publishing. We aim to process papers 
as quickly as possible whilst maintaining high quality of published work. The open access format will offer authors wide visibility for their work and provide readers free access to all published papers.

Along with the Editorial Board, I invite you to submit your process technology related research to Processes.

(C) 2013 by the authors; licensee MDPI, Basel, Switzerland. This article is an open access article distributed under the terms and conditions of the Creative Commons Attribution license (http://creativecommons.org/licenses/by/3.0/). 